\title{
Retrospective study on the efficacy of a low- carbohydrate diet for impaired glucose tolerance
}

This article was published in the following Dove Press journal:

Diabetes, Metabolic Syndrome and Obesity: Targets and Therapy

13 June 2014

Number of times this article has been viewed

\author{
Satoshi Maekawa' \\ Tetsuya Kawahara ${ }^{2}$ \\ Ryosuke Nomura' \\ Takayuki Murase' \\ Yasuyoshi Ann' \\ Masayuki Oeholm' \\ Masaru Harada ${ }^{3}$ \\ 'Department of Gastroenterology \\ and Hepatology, ${ }^{2}$ Division of \\ Endocrinology and Metabolism, \\ Department of Internal Medicine, \\ Japan Labor Health and Welfare \\ Organization, Niigata Rosai Hospital, \\ Joetsu, Niigata, Japan; ${ }^{3}$ Third \\ Department of Internal Medicine, \\ University of Occupational and \\ Environmental Health, Iseigaoka, \\ Yahata-nishi-ku, Kitakyushu, Fukuoka, \\ Japan
}

Correspondence: Satoshi Maekawa Department of Gastroenterology and Hepatology, Japan Labor Health and Welfare Organization Niigata Rosai Hospital, I-7-12 Touncho,

Joetsu, Niigata, Japan

$\mathrm{Tel}+8 \mid 255433$ I 23

$\mathrm{Fax}+81255445210$

Emails5083m@niirou.jp
Background: In recent years, the number of people with impaired glucose tolerance (IGT) has increased steadily worldwide. It is clear that the prevention of diabetes is important from the perspective of public health, medical care, and economics. It was recently reported that a low-carbohydrate diet (LCD) is useful for achieving weight loss and glycemic control, but there is no information about the effects of the LCD on IGT. We designed a 7-day in-hospital educational program focused on the LCD for IGT.

Methods: The subjects were 72 patients with IGT (36 in the LCD group and 36 in the control group) who were enrolled from April 2007-March 2012 and followed for 12 months. We retrospectively compared the LCD group with the control group.

Results: In 69.4\% of the LCD group, blood glucose was normalized at 12 months and the 2-hour plasma glucose level in the oral glucose tolerance test (OGTT) was reduced by $33 \mathrm{mg} / \mathrm{dL}$. In addition, the incidence of diabetes was significantly lower in the LCD group than in the control group at 12 months $(0 \%$ versus $13.9 \%, P=0.02)$. The LCD group showed a significant decrease in fasting plasma glucose, hemoglobin $\mathrm{A}_{1 \mathrm{c}}$, the homeostasis model of assessment of insulin resistance value, body weight and serum triglycerides (TGs) at 12 months, while there was a significant increase of the serum high-density lipoprotein (HDL) cholesterol level.

Conclusion: The LCD is effective for normalizing blood glucose and preventing progression to type 2 diabetes in patients with IGT.

Keywords: type 2 diabetes, low-carbohydrate diet, impaired glucose tolerance

\section{Introduction}

Impaired glucose tolerance (IGT) is a less severe form of hyperglycemia that represents an intermediate stage in the development of type 2 diabetes. ${ }^{1-3}$ Twenty-five percent to $75 \%$ of individuals with IGT progress to diabetes within a decade of diagnosis. ${ }^{4}$ In recent years, the numbers of new patients with type 2 diabetes and IGT have steadily increased around the world, and it is estimated that over 300 million people will have type 2 diabetes by the year 2025..$^{5}$ A number of large-scale clinical studies have made it clear that IGT is a major risk factor for cardiovascular disease.$^{6-8}$ It is also clear that prevention of diabetes before its onset and aggressive treatment of this disease at an early stage is important from the perspective of public health, medical care, and economics. ${ }^{9}$ In this context, several intervention studies have demonstrated the positive effects of lifestyle modification. ${ }^{9-14}$

It was recently reported that a low-carbohydrate diet (LCD) is useful for promoting weight loss and improving glycemic control, ${ }^{15-24}$ but it remains unclear whether the LCD can normalize blood glucose in IGT patients and prevent progression to type 2 diabetes. 
Against this background, we designed a 7-day in-hospital educational program focused on the LCD for IGT. The aim of the present study was to assess the efficacy of this program combined with diabetes education and support at 3-month intervals for normalizing blood glucose in IGT patients and preventing progression from IGT to type 2 diabetes.

\section{Methods}

The participants in the present study were 72 Japanese patients with IGT who were enrolled from April 2007-March 2013 at Japan Labour Health and Welfare Organization Niigata Rosai Hospital (Joetsu, Japan). We screened patients aged 20-75 years with a body mass index $(\mathrm{BMI})<35 \mathrm{~kg} / \mathrm{m}^{2}$, fasting glucose $<126 \mathrm{mg} / \mathrm{dL}$, and hemoglobin $\mathrm{A}_{1 \mathrm{c}}\left(\mathrm{HbA}_{1 \mathrm{c}}\right)<7.0 \%$. Patients were eligible for this study if they had IGT, which was defined as a glucose level of 140-199 mg/dL at 2 hours after a $75 \mathrm{~g}$ oral glucose load according to the 2003 American Diabetes Association criteria. In addition, all of the subjects were confirmed to have a serum triglyceride (TG) level $<300$ $\mathrm{mg} / \mathrm{dL}$ and a serum low-density lipoprotein (LDL) cholesterol level $<200 \mathrm{mg} / \mathrm{dL}$. None of the patients were taking any medications that could influence glycemic control. Patients were excluded if they were pregnant or breastfeeding, had a serum creatinine level $\geq 2 \mathrm{mg} / \mathrm{dL}$, had liver dysfunction, had gastrointestinal problems that would prevent them from following the prescribed diet, had active cancer, or were participating in another trial. This study was performed in conformity with the Declaration of Helsinki. Written informed consent was obtained from all patients and the Ethics Committee of the Japan Labor Health and Welfare Organization Niigata Rosai Hospital approved this study. We obtained consent for publication of all the materials in this article, including the individual information contained in the tables.

\section{Interventions}

Eligible participants were assigned to one of two groups, either a group that was hospitalized for 7 days of LCD education (LCD group) or a group that was not hospitalized and had no education (control group). The low-carbohydrate, unrestricted calorie diet aimed at a maximum daily intake of $120 \mathrm{~g}$ of carbohydrates. The objectives of the 7-day inhospital educational program were to create motivation, provide information about diabetes and IGT, and change the patient's eating habits. Lessons were taught by nutritionists, pharmacologists, nurses, and physicians on a one-to-one or group basis. After the hospital stay, we provided individual support sessions every 3 months with nutritionists, nurses, and physicians. In the control group, participants were given general information about diabetes and IGT. Their physicians also provided diabetes information brochures with general instructions on diet and lifestyle improvement, but there was no individual instruction or formal group counseling.

\section{7-day LCD education program}

The LCD group was admitted to hospital for 7 days to participate in an educational program. On the first day of the program, a physician gave a lecture about the LCD using slides that lasted for 60 minutes. On the second day, the subjects received individual lessons from nutritionists, pharmacologists, and nurses. After that, they ate the LCD every day and studied the diet using a textbook that was given to them. In compliance with the LCD, rice (the main dish) was offered at lunchtime only. The target was a total intake of $1,300 \mathrm{kcal}$ per day. The nutritional composition of the food was $30 \%$ carbohydrates, $25 \%$ protein, and $45 \%$ fat. On the fifth day, the subjects completed some tests on the LCD (30 questions, true/false test), and discussed their diet with nutritionists, nurses, and physicians at a lunch meeting on the LCD. After that, they reviewed the diet and were discharged from hospital.

\section{Follow-up}

Subjects in both groups were asked to attend outpatient guidance sessions every 3 months and were also reviewed by their physicians at 3-month intervals. Body weight was measured and blood and urine samples were collected. The general health of each subject was assessed, and the results of the laboratory tests were explained by the physicians, who gave advice about diabetes or IGT for 5-10 minutes at every interview. Thereafter, subjects in the LCD group received 10- to 15-minute individual counseling sessions. We emphasized the total carbohydrate intake of less than $120 \mathrm{~g}$ per day without restricting total calories or fat. A $75 \mathrm{~g}$ oral glucose tolerance test (OGTT), fasting plasma glucose, fasting plasma insulin, serum LDL cholesterol level, serum high-density lipoprotein (HDL) cholesterol, and serum TGs were measured at every 3 -month visit. The study was continued for 12 months.

\section{Laboratory investigations}

All blood samples were sent to the central laboratory at Niigata Rosai Hospital, and aliquots were stored at $-70^{\circ} \mathrm{C}$ until analysis. Plasma glucose levels were determined by the glucose oxidation method (chemical reagents and Glucose ADAMS GA-1171 Analyzer; Arkray, Kyoto, Japan). HbA was measured by high-performance liquid chromatography 
(HPLC; ADAMS A1C HA-8181; Arkray). The value of $\mathrm{HbA}_{1 \mathrm{c}}(\%)$ was estimated as a National Glycohemoglobin Standardization Program (NGSP) equivalent value (\%) derived from the Japanese Diabetes Society (JDS) value and calculated by the formula $\mathrm{HbA}_{1 \mathrm{c}}(\%)=\mathrm{HbA}_{1 \mathrm{c}}(\mathrm{JDS})(\%)+$ $0.4 \% .{ }^{25}$ Serum LDL cholesterol and serum HDL cholesterol levels were measured by the direct method without deposition (Sekisui Medical H-7700; Hitachi Ltd, Tokyo, Japan). Serum TGs were measured by the cholesterol oxidation enzyme and enzymatic colorimetry methods (Sekisui Medical H-7700). Plasma insulin levels were measured with an enzyme immunometric assay (Immulite Autoanalyzer; Diagnostic Products Corporation, Los Angeles, CA, USA), for which the coefficient of variation was $2.5 \%$.

\section{Statistical analysis}

Intention-to-treat analysis was done on all patients in their assigned groups, regardless of whether they actually performed the specified intervention. Results are expressed as the mean \pm standard deviation. The differences between baseline values and those after 12 months of treatment were evaluated using the paired $t$-test for continuous variables. Differences between the two groups were assessed using the unpaired $t$-test for continuous variables and by the chi-square test or Fisher's exact probability test for categorical variables because the distribution of each variable did not differ significantly between the two groups. In all analyses, $P<0.05$ was considered significant and analyses were performed with StatView software (v5; BrainPower Inc., Calabasas, CA, USA).

\section{Results}

\section{Patients}

From April 2007-March 2013, we assigned 72 participants to the two groups (36 to the LCD group and 36 to the control group). There were no significant differences in the baseline characteristics between the two groups (Table 1).

\section{Changes in glucose parameters}

After 12 months, the 2-hour plasma glucose level of the LCD group showed a significant decrease in comparison with baseline in the OGTT $(P<0.001)$. On the other hand, the control group showed a significant increase in the 2-hour plasma glucose compared with baseline $(P<0.01)$. After 12 months, the 2-hour plasma glucose level in the OGTT was significantly lower in the LCD group than in the control group $(P<0.001$; Table 2 and Figure 1$)$. In the
Table I Baseline characteristics of the patients

\begin{tabular}{|c|c|c|c|}
\hline Characteristics & $\begin{array}{l}\text { LCD group } \\
(n=36)\end{array}$ & $\begin{array}{l}\text { Control group } \\
(n=36)\end{array}$ & $P$-value \\
\hline Age, years & $59.3 \pm 10.2$ & $60.1 \pm 8.1$ & 0.7 \\
\hline Female, number (\%) & $20(56)$ & 14 (39) & 0.16 \\
\hline Body weight, kg & $68.5 \pm 10.1$ & $67.3 \pm 6.4$ & 0.56 \\
\hline $\mathrm{BMI}, \mathrm{kg} / \mathrm{m}^{2}$ & $26.8 \pm 2.7$ & $26.1 \pm 1.5$ & 0.16 \\
\hline $\begin{array}{l}\text { Fasting plasma glucose, } \\
\mathrm{mg} / \mathrm{dL}\end{array}$ & $104.9 \pm 8.8$ & $102.9 \pm 7.9$ & 0.31 \\
\hline $\begin{array}{l}\text { Plasma glucose at } \\
2 \text { hours after an oral } \\
\text { glucose load, } \mathrm{mg} / \mathrm{dL}\end{array}$ & $160.8 \pm 16.9$ & $159.4 \pm 13.6$ & 0.7 \\
\hline $\mathrm{HbA}_{\mathrm{Ic}}, \%$ & $6.0 \pm 0.4$ & $6.1 \pm 0.4$ & 0.27 \\
\hline $\begin{array}{l}\text { Fasting plasma insulin, } \\
\mu \mathrm{U} / \mathrm{mL}\end{array}$ & $8.5 \pm 5.3$ & $9.1 \pm 3.2$ & 0.6 \\
\hline HOMA-IR & $2.2 \pm 1.5$ & $2.3 \pm 0.8$ & 0.67 \\
\hline $\begin{array}{l}\text { Serum LDL cholesterol, } \\
\mathrm{mg} / \mathrm{dL}\end{array}$ & $|28.8 \pm 3| . \mid$ & $129.6 \pm 28.2$ & 0.91 \\
\hline $\begin{array}{l}\text { Serum HDL cholesterol, } \\
\mathrm{mg} / \mathrm{dL}\end{array}$ & $56.4 \pm 12.3$ & $54.1 \pm 12.4$ & 0.42 \\
\hline Serum TGs, mg/dL & $131.4 \pm 69.2$ & $|35.4 \pm 40|$. & 0.77 \\
\hline
\end{tabular}

LCD group, 25 patients achieved resolution of IGT with normalization of glucose levels, eleven patients still had IGT, and no patient developed type 2 diabetes. In the control group, three patients achieved resolution of IGT, 28 patients still had IGT, and five patients progressed

Table 2 Endpoints at 12 months

\begin{tabular}{|c|c|c|c|}
\hline Endpoints & $\begin{array}{l}\text { LCD group } \\
(n=36)\end{array}$ & $\begin{array}{l}\text { Control group } \\
(n=36)\end{array}$ & $P$-value \\
\hline $\begin{array}{l}\text { Plasma glucose at } 2 \text { hours } \\
\text { after oral glucose load, } \\
\mathrm{mg} / \mathrm{dL}\end{array}$ & $127.8 \pm 27 . \mid$ & $172.6 \pm 25.9$ & $<0.001$ \\
\hline $\begin{array}{l}\text { Normalization rate of } \\
\text { IGT, number (\%) }\end{array}$ & $25(69.4)$ & $3(8.3)$ & $<0.001$ \\
\hline $\begin{array}{l}\text { Incidence rate of diabetes, } \\
\text { number (\%) }\end{array}$ & $0(0)$ & $5(13.9)$ & 0.02 \\
\hline $\begin{array}{l}\text { Fasting plasma glucose, } \\
\mathrm{mg} / \mathrm{dL}\end{array}$ & $99.1 \pm 8.3$ & $110.2 \pm 12.7$ & $<0.001$ \\
\hline $\mathrm{HbA}_{\mid \mathrm{c}}, \%$ & $5.6 \pm 0.4$ & $6.4 \pm 0.5$ & $<0.001$ \\
\hline Body weight, kg & $61.6 \pm 9.6$ & $68.5 \pm 5.9$ & $<0.001$ \\
\hline $\begin{array}{l}\text { Fasting plasma insulin, } \\
\mu \mathrm{U} / \mathrm{mL}\end{array}$ & $6.0 \pm 4.2$ & $9.6 \pm 2.9$ & $<0.001$ \\
\hline HOMA-IR & $1.5 \pm 1.0$ & $2.6 \pm 1.0$ & $<0.001$ \\
\hline $\begin{array}{l}\text { Serum LDL cholesterol, } \\
\mathrm{mg} / \mathrm{dL}\end{array}$ & $125.4 \pm 33.3$ & $133.1 \pm 23.7$ & 0.26 \\
\hline $\begin{array}{l}\text { Serum HDL cholesterol, } \\
\mathrm{mg} / \mathrm{dL}\end{array}$ & $63.3 \pm 16.2$ & $50.3 \pm 10.1$ & $<0.001$ \\
\hline Serum TGs, mg/dL & $97.4 \pm 57.9$ & $150.6 \pm 30.5$ & $<0.001$ \\
\hline
\end{tabular}

Abbreviations: $\mathrm{HbA}_{1 \mathrm{c}}$, hemoglobin $\mathrm{A}_{1 \mathrm{c}}$; $\mathrm{HDL}$, high-density lipoprotein; HOMA-IR, homeostasis model assessment of insulin resistance; IGT, impaired glucose tolerance; LCD, low-carbohydrate diet; LDL, low-density lipoprotein; TGs, triglycerides. 


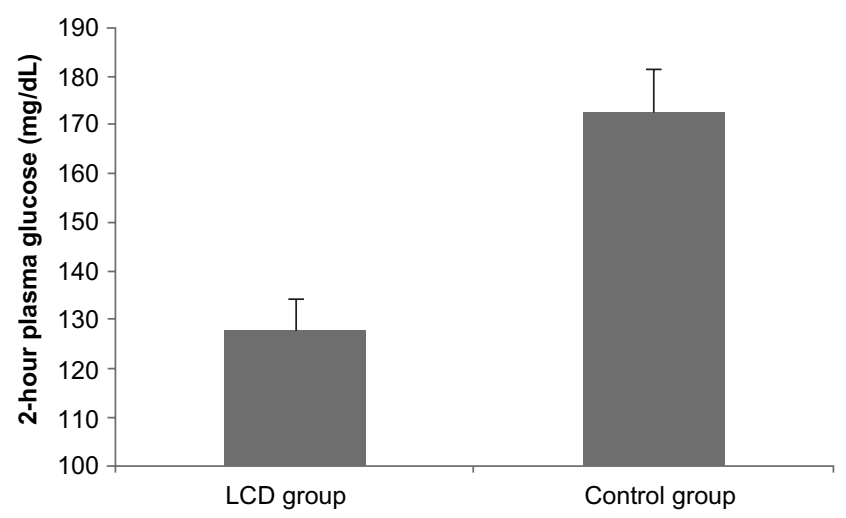

Figure I Plasma glucose at 2 hours after an oral glucose load (12-month endpoint). Notes: $y$-axis shows 2-hour plasma glucose $(\mathrm{mg} / \mathrm{dL})$; data are shown as the mean \pm standard error for each group.

Abbreviation: LCD, low-carbohydrate diet.

A

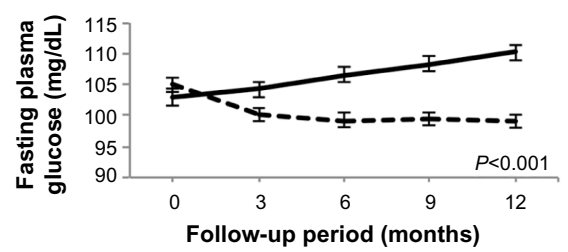

C

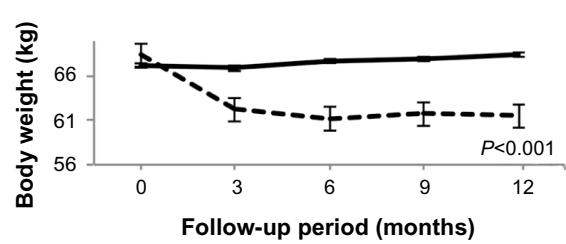

E

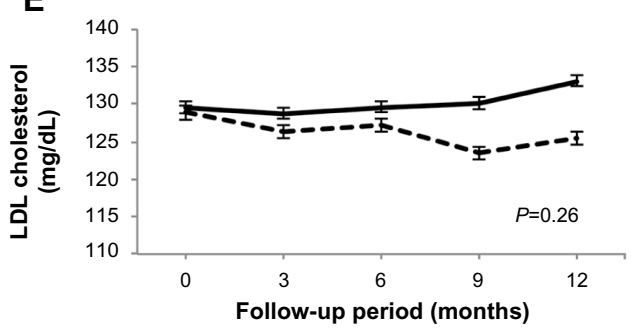

G

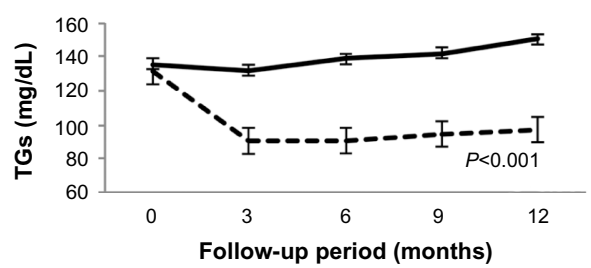

to type 2 diabetes. The IGT normalization rate was significantly higher in the LCD group $(25 / 36,69.4 \%)$ than in the control group $(3 / 36,8 \%)(P<0.001)$, while the incidence of diabetes was significantly lower in the LCD group $(0 / 36,0 \%)$ than in the control group $(5 / 36,13.9 \%)$ $(P=0.02)$. Fasting plasma glucose and $\mathrm{HbA}_{1 \mathrm{c}}$ both showed a significant decrease compared with baseline in the LCD group ( $P<0.01$ and $P<0.001$, respectively). On the other hand, both parameters increased significantly compared with baseline in the control group $(P<0.01$ and $P<0.001$, respectively). Changes in fasting plasma glucose and $\mathrm{HbA}_{1 \mathrm{c}}$ over the 1-year period were significantly different between the two groups $(P<0.001$; Figure $2 \mathrm{~A}$ and $\mathrm{B})$.
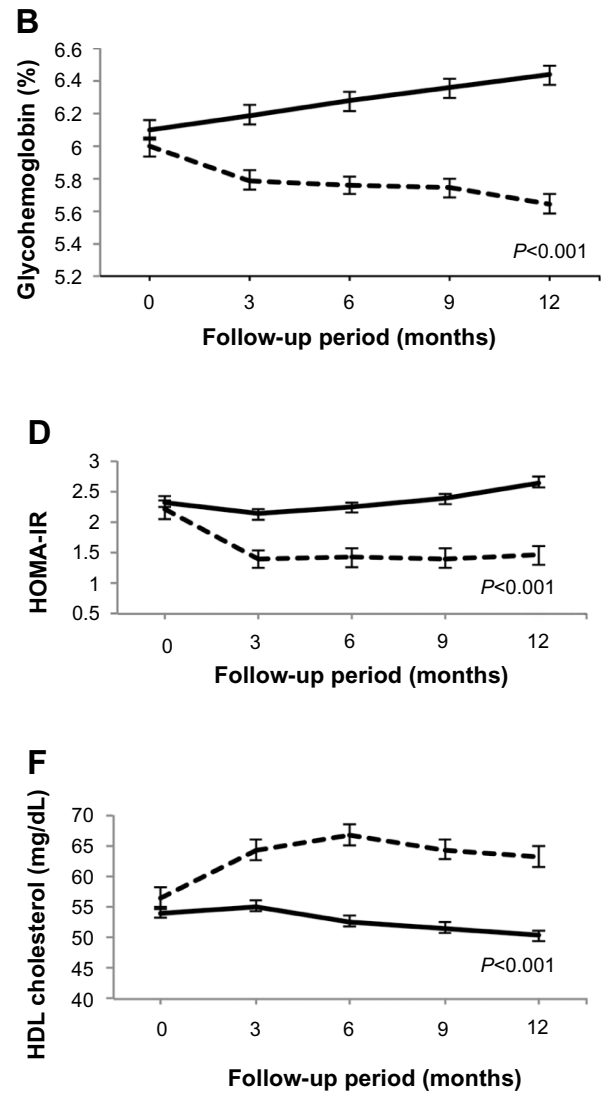

Figure 2 (A) Profile of fasting plasma glucose; (B) glycohemoglobin; (C) body weight; (D) HOMA-IR; (E) LDL cholesterol; (F) HDL cholesterol; and (G) TGs in each group. Notes: Data points represent the mean \pm standard error for each group at the indicated times. The dashed lines and the solid lines represent the LCD group and the control group, respectively. ------ LCD group, _ control group. The HOMA-IR was calculated as fasting insulin $(\mu \mathrm{U} / \mathrm{mL}) \times$ fasting glucose $(\mathrm{mg} / \mathrm{dL}) \div 405$.

Abbreviations: HDL, high-density lipoprotein; HOMA-IR, homeostasis model of assessment of insulin resistance; LCD, low-carbohydrate diet; LDL, low-density lipoprotein; TGs, triglycerides. 


\section{Changes in body weight}

After 12 months, the LCD group showed a significant decrease in weight compared with baseline $(P<0.001)$. In contrast, the body weight of the control group increased significantly compared with baseline $(P<0.01)$. The weight of the LCD group was significantly lower than that of the control group at 12 months $(P<0.001$; Table 2 and Figure $2 \mathrm{C})$.

\section{Changes in insulin resistance}

At 12 months, both hyperinsulinemia and homeostasis model of assessment of insulin resistance (HOMA-IR) were improved in the LCD group compared with the control group $(P<0.001$; Table 2$)$. In the LCD group, HOMA-IR showed a significant decrease compared with baseline $(P<0.01)$, while HOMA-IR increased significantly relative to baseline in the control group $(P<0.01)$. The 12-month change in HOMA-IR was significantly greater in the LCD group than in the control group $(P<0.001$; Figure 2D).

\section{Changes in lipids - LDL cholesterol, HDL cholesterol, and TGs}

The serum LDL cholesterol level of the LCD group was slightly decreased ( $P=0.55$ versus baseline) and that of the control group was slightly increased at 12 months ( $P=0.53$ versus baseline), but there was no significant difference between the two groups ( $P=0.26$; Table 2 and Figure 2E). After 12 months, the serum HDL cholesterol level of the LCD group showed a significant increase $(P<0.001)$, while that of the control group decreased significantly $(P<0.001)$. Thus, the 12-month changes of serum HDL cholesterol were significantly different between the two groups $(P<0.001$; Table 2 and Figure 2F). After 12 months, serum TGs significantly decreased in the LCD group $(P<0.01)$, and significantly increased in the control group $(P<0.01)$. Thus, the 12-month changes of TGs were significantly different between the two groups $(P<0.001$; Table 2 and Figure $2 \mathrm{G})$.

\section{Adverse events}

None of the subjects in either group experienced any adverse events.

\section{Discussion}

The present study demonstrated that a 7-day in-hospital educational program focused on a LCD is effective for blood glucose normalization in IGT patients and for preventing progression from IGT to type 2 diabetes. The blood glucose normalization rate was $69.4 \%$ in the LCD group, which is higher than previously reported with a low-fat diet
(LFD) $(26 \%-47 \%){ }^{12,26}$ In the OGTT, the 2-hour plasma glucose level was reduced by $33 \mathrm{mg} / \mathrm{dL}$ in the LCD group, which was greater than the decrease in previous LFD studies $(22-29 \mathrm{mg} / \mathrm{dL}) .^{12,27}$ The 1-year incidence of diabetes among IGT patients in the control group was $13.9 \%$, which was within the range suggested by epidemiological data $(1.5 \%-15.7 \%) .{ }^{11,26-30}$ On the other hand, the 1-year incidence of diabetes was $0 \%$ in the LCD group, which was significantly lower than in the control group $(P=0.02)$ or in previous LFD studies $(2.0 \%-12.5 \%){ }^{10,26,28}$ Although we did not assess the long-term effects of the LCD, we consider that this diet reduces progression to diabetes in the IGT population more effectively than a LFD.

The following reasons can be suggested for the high blood glucose normalization rate. First, it is likely that participants with IGT have glucose intolerance due to excessive carbohydrate intake; hence, restriction of their carbohydrate intake leads to blood glucose normalization. In fact, the blood glucose level of most subjects in the LCD group decreased after a few days of hospitalization in comparison with baseline. Second, because the LCD does not regulate the total calorie intake and allows patients to eat enough of various foods, it seems that the LCD is easier to understand and conform to than the LFD. Third, several studies have indicated that the LCD is more effective for achieving weight loss than the LFD. ${ }^{15-24}$ The LCD group achieved a mean weight loss of $10.6 \%$ at 12 months, which was within the range suggested by previous reports on low-carbohydrate therapies $(3.4 \%-10.9 \%){ }^{18-20}$ This marked weight reduction with the LCD may have led to blood glucose normalization in the LCD group and prevented progression to type 2 diabetes. Moreover, HOMA-IR was significantly lower at 12 months compared with baseline in the LCD group. Weight reduction probably contributed to the improvement of insulin resistance.

In this study, we observed a significant increase of HDL cholesterol and a significant decrease of TGs; however, there was no significant alteration of the LDL cholesterol level. Recent studies have shown that the LCD is better for achieving weight loss, decreasing TGs, and increasing HDL cholesterol, while the LFD is better for decreasing total cholesterol and LDL cholesterol levels. ${ }^{24}$ We obtained similar results, which suggests that the LCD might have a weak effect on reducing LDL cholesterol.

We designed the 7-day in-hospital educational program so that it focused on the LCD. Subjects in the LCD group could study the LCD, actually eat the diet, and change their eating habits during a 7-day hospital stay. On the last 
hospital day, most subjects already displayed weight loss and a decrease in glucose, and they were praised for achieving this goal, which might have increased their confidence and motivation. The LCD group also received 10- to 15-minute individual counseling sessions every 3 months, and this level of support was sufficient for maintaining their knowledge and motivation.

Our study had several limitations. First, it was a casecontrol study and we could not determine whether both groups had the same unknown bias that affected glucose tolerance. Second, we treated a small number of Japanese patients for a short period. Therefore, a large-scale trial would be needed to confirm the generality of our findings. Third, we did not have a LFD group as one of the study groups; hence, we could not assess the superiority of the LCD over the LFD.

\section{Conclusion}

Our study demonstrated that a 7-day LCD education program and periodic interval follow-up are effective for achieving blood glucose normalization and preventing progression to type 2 diabetes in patients with IGT. The LCD significantly decreased the 2-hour plasma glucose in the OGTT, as well as fasting plasma glucose, $\mathrm{HbA}_{1 \mathrm{c}}$, HOMA-IR, body weight, and serum TGs at 12 months, while significantly increasing the serum HDL cholesterol level. However, a large-scale study is necessary to confirm the efficacy of the LCD for IGT.

\section{Disclosure}

The authors report no conflicts of interest in this work.

\section{References}

1. National Diabetes Data Group. Classification and diagnosis of diabetes mellitus and other categories of glucose intolerance. Diabetes. 1979;28(12):1039-1057.

2. Saad MF, Knowler WC, Pettitt DJ, Nelson RG, Charles MA, Bennett PH. A two-step model for development of non-insulin-dependent diabetes. Am J Med. 1991;90(2):229-235.

3. Lillioja S, Mott DM, Howard BV, et al. Impaired glucose tolerance as a disorder of insulin action. Longitudinal and cross-sectional studies in Pima Indians. N Engl J Med. 1988;318(19):1217-1225.

4. Saad MF, Knowler WC, Pettitt DJ, Nelson RG, Mott DM, Bennett PH. The natural history of impaired glucose tolerance in the Pima Indians. N Engl J Med. 1988;319(23):1500-1506.

5. King H, Aubert RE, Herman WH. Global burden of diabetes, 1995-2025: prevalence, numerical estimates, and projections. Diabetes Care. 1998;21(9):1414-1431.

6. DECODE Study Group. Glucose tolerance and mortality: comparison of WHO and American Diabetes Association diagnostic criteria. The DECODE study group. European Diabetes Epidemiology Group. Diabetes Epidemiology: Collaborative analysis Of Diagnostic criteria in Europe. Lancet. 1999;354(9179):617-621.

7. Fujishima M, Kiyohara Y, Kato I, et al. Diabetes and cardiovascular disease in a prospective population survey in Japan: The Hisayama Study. Diabetes. 1996;45 Suppl 3:S14-S16.
8. Tominaga M, Eguchi H, Manaka H, Igarashi K, Kato T, Sekikawa A. Impaired glucose tolerance is a risk factor for cardiovascular disease, but not impaired fasting glucose. The Funagata Diabetes Study. Diabetes Care. 1999;22(6):920-924.

9. Harris MI. Diabetes in America: epidemiology and scope of the problem. Diabetes Care. 1998;21 Supp1 3:C11-C14.

10. Kawahara $\mathrm{T}$, Takahashi $\mathrm{K}$, Inazu $\mathrm{T}$, et al. Reduced progression to type 2 diabetes from impaired glucose tolerance after a 2-day in-hospital diabetes educational program: the Joetsu Diabetes Prevention Trial. Diabetes Care. 2008;31(10):1949-1954.

11. Pan XR, Li GW, Hu YH, et al. Effects of diet and exercise in preventing NIDDM in people with impaired glucose tolerance. The Da Qing IGT and Diabetes Study. Diabetes Care. 2008;20(4):537-544.

12. Knowler WC, Barrett-Connor E, Fowler SE, et al; Diabetes Prevention Program Research Group. Reduction in the incidence of type 2 diabetes with lifestyle intervention or metformin. $N$ Engl $J$ Med. 2002;346(6):393-403.

13. Herman WH, Hoerger TJ, Brandle M, et al; Diabetes Prevention Program Research Group. The cost-effectiveness of lifestyle modification or metformin in preventing type 2 diabetes in adults with impaired glucose tolerance. Ann Intern Med. 2005;142(5):323-332.

14. Genuth S, Alberti KG, Bennett P, et al; Expert Committee on the Diagnosis and Classification of Diabetes Mellitus. Follow-up report on the diagnosis of diabetes mellitus. Diabetes Care. 2003;26(11):3160-3167.

15. Shai I, Schwarzfuchs D, Henkin Y, et al; Dietary Intervention Randomized Controlled Trial (DIRECT) Group. Weight loss with a low-carbohydrate, Mediterranean, or low-fat diet. $N$ Engl $J$ Med. 2008;359(3):229-241.

16. Busetto L, Marangon M, De Stefano F. High-protein lowcarbohydrate diets: what is the rationale? Diabetes Metab Res Rev. 2011;27(3):230-232.

17. Wycherley TP, Brinkworth GD, Keogh JB, Noakes M, Buckley JD, Clifton PM. Long-term effects of weight loss with a very low carbohydrate and low fat diet on vascular function in overweight and obese patients. J Intern Med. 2009;267(5):452-461.

18. Yarcy WS Jr, Westman EC, McDuffie JR, et al. A randomized trial of a low-carbohydrate diet vs orlistat plus a low-fat diet for weight loss. Arch Intern Med. 2010;170(2):136-145.

19. Davis NJ, Tomuta N, Schechter C, et al. Comparative study of the effects of a 1-year dietary intervention of a low-carbohydrate diet versus a low-fat diet on weight and glycemic control in type 2 diabetes. Diabetes Care. 2009;32(7):1147-1152.

20. Foster GD, Wyatt HR, Hill JO, et al. Weight and metabolic outcomes after 2 years on a low-carbohydrate versus low-fat diet: a randomized trial. Ann Intern Med. 2010;153(3):147-157.

21. Sasakabe T, Haimoto H, Umegaki H, Wakai K. Effects of a moderate low-carbohydrate diet on preferential abdominal fat loss and cardiovascular risk factors in patients with type 2 diabetes. Diabetes Metab Syndr Obes. 2011;4:167-174.

22. Vetter ML, Wade A, Womble LG, Dalton-Bakes C, Wadden TA, Igbal N. Effect of a low-carbohydrate diet versus a low-fat, calorie-restricted diet on adipokine levels in obese, diabetic participants. Diabetes Metab Syndr Obes. 2010;3:357-361.

23. Haimoto H, Sasakabe T, Wakai K, Umegaki H. Effects of a low-carbohydrate diet on glycemic control in outpatients with severe type 2 diabetes. Nutr Metab (Lond). 2009;6:21.

24. Foster GD, Wyatt HR, Hill JO, et al. A randomized trial of a low-carbohydrate diet for obesity. $N$ Engl J Med. 2003;348(21): 2082-2090.

25. Seino Y, Nanjo K, Tajima N. The Committee of Japan Diabetes Society on the diagnostic criteria of diabetes mellitus: Report of the Committee on the classification and diagnostic criteria of diabetes mellitus. $J$ Diabetes Invest. 2010;1:212-228.

26. Chiasson JL, Josse RG, Gomis R, Hanefeld M, Karasik A, Laakso M; STOP-NIDDM Trail Research Group. Acarbose for prevention of type 2 diabetes mellitus: the STOP-NIDDM randomised trial. Lancet. 2002;359(9323):2027-2077. 
27. Eriksson KF, Lingärde E. Prevention of type 2 (non-insulin-dependent) diabetes mellitus by diet and physical exercise. The 6-year Malmö feasibility study. Diabetologia. 1991;34(12):891-898.

28. Tuomilehto J, Lindström J, Eriksson JG, et al; Finnish Diabetes Prevention Study Group. Prevention of type 2 diabetes mellitus by changes in lifestyle among subjects with impaired glucose tolerance. N Engl J Med. 2001;344(18):1343-1350.
29. Harris MI. Impaired glucose tolerance - prevalence and conversion to NIDDM. Diabet Med. 1996;13(3 Suppl 2):S9-S11.

30. Modan M, Karasik A, Halkin H, et al. Effects of past and concurrent body mass index on prevalence of glucose intolerance and type 2 (non-insulin-dependent) diabetes and on insulin response. The Israel study of glucose intolerance, obesity and hypertension. Diabetologia. $1986 ; 29(2): 82-89$.

\section{Publish your work in this journal}

Diabetes, Metabolic Syndrome and Obesity: Targets and Therapy is an international, peer-reviewed open-access journal committed to the rapid publication of the latest laboratory and clinical findings in the fields of diabetes, metabolic syndrome and obesity research Original research, review, case reports, hypothesis formation, expert opinion and commentaries are all considered for publication. The manuscript management system is completely online and includes a very quick and fair peer-review system, which is all easy to use. Visit http://www.dovepress.com/testimonials.php to read real quotes from published authors.

Submit your manuscript here: http://www.dovepress.com/diabetes-metabolic-syndrome-and-obesity-targets-and-therapy-journal 